\title{
SISTEM MONITORING KINERJA SUB BAGIAN OPERATOR SCADA MENGGUNAKAN AGILE DEVELOPMENT METHODS STUDI KASUS PT. CLADTEK BI METAL MANUFACTURING
}

\author{
Indah Kusuma Dewi ${ }^{1}$, Randa Amalta Saputra ${ }^{2}$ \\ ${ }^{1,2}$ Universitas Ibnu Sina; Jalan Teuku Umar, Lubuk Baja, Batam, Kepulauan Riau, Telp. 0778- \\ 4083113 \\ ${ }^{3}$ Program Studi Teknik Informatika, Fakultas Teknik - Universitas Ibnu Sina, Batam \\ e-mail: *11indah@uis.ac.id, ${ }^{2}$ randa@uis.ac.id
}

\begin{abstract}
Abstrak
PT. Cladtek BI Metal Manufacturing merupakan perusahaan yang bergerak dibidang jasa industri untuk berbagai pekerjaan mengenai material logam, khususnya proses Cladding, Weld Overlay dan Lining pada pipa baja karbon untuk keperluan industri. Pada departement Production memiliki karyawan berjumlah 19 orang terdiri dari 1 orang supervisor, 3 orang foreman dan 15 orang pada sub bagian operator scada. Satu orang foreman membawahi 5 orang karyawan untuk memonitoring kinerja dan pemberian nilai. Namun sangat disayangkan, bahwa performa tim hanya dicatat secara manual pada sebuah buku catatan (log book) oleh setiap foreman (atasan) yang membuat sistem penilaian setiap karyawan menjadi lebih sulit karena tidak adanya visualisasi data yang mempermudahan manajemen mengambil keputusan. Dalam penelitian ini digunaka metode Agile Development untuk mempermudah proses pengambilan spesifikasi sistem dan alur bisnis dan keputusan. Metode agile software development adalah pengembangan perangkat lunak berdasarkan pengembangan iterative dan incremental dimana syarat dan solusi berubah melalui kolaborasi antara selft organizing dan cross functional tim. Sistem ini dibangun dengan Bahasa pemograman Bahasa php, database mysql yang berbasis web dengan tujuan menghasilkan suatu sistem informasi monitoring yang terstruktur dan dapat menampilkan data analisis dalam sebuah dashboard untuk mengendalikan kinerja sub bagian scada di PT. Cladtek BI Metal Manufacturing menggunakan model scrum dan mempermudah penilaian dan kontrol terhadap daftar kerja dan proyek yang masih manual.
\end{abstract}

Kata kunci- Sistem Monitoring Kinerja, Agile Development Methods, Penilaian Kinerja Karyawan

Abstract
PT. Cladtek BI Metal Manufacturing is a company engaged in industrial services for
various jobs regarding metal materials, especially the Cladding, Weld Overlay and Lining
processes on carbon steel pipes for industrial use. The Production department has 19
employees consisting of 1 supervisor, 3 foreman and 15 people in the Scada operator
subdivision. One foreman supervises 5 employees for performance monitoring and scoring.
Unfortunately, team performance is only recorded manually in a log book by each foreman
(superiors) which makes the appraisal system for each employee more difficult because there is
no data visualization that makes it easy for management to make decisions. In this study, the
Agile Development method is used to simplify the process of making system specifications and
business flows and decisions. The agile software development method is software development
based on iterative and incremental development where terms and solutions change through
collaboration between selft organizing and cross-functional teams. This system was built with


the PHP language programming language, a web-based mysql database with the aim of producing a structured monitoring information system and being able to display analytical data in a dashboard to control the performance of the Scada subsection at PT. Cladtek BI Metal Manufacturing uses the Scrum model and makes it easy to assess and control manual work lists and projects.

Keywords - Performance Monitoring System, Agile Development Methods, Employee Performance Appraisal

\section{PENDAHULUAN}

PT. Cladtek BI Metal Manufacturing merupakan perusahaan yang bergerak dibidang jasa industri untuk berbagai pekerjaan mengenai material logam, khususnya proses Cladding, Weld Overlay dan Lining pada pipa baja karbon untuk keperluan industri. Untuk menunjang hal tersebut PT. Cladtek BI Metal Manufacturing memiliki banyak departemen dan tim yang memiliki tanggung jawab besar pada setiap proses bisnis perusahaan.

Pada PT. Cladtek BI Metal Manufacturing penulisan ini difokuskan kepada sub bagian Departemen Production pada bagian sub bagian operator scada. Pada departement Production memiliki karyawan berjumlah 19 orang terdiri dari 1 orang supervisor, 3 orang foreman dan 15 orang pada sub bagian operator scada. Satu orang foreman membawahi 5 orang karyawan untuk memonitoring kinerja dan pemberian nilai. Namun sangat disayangkan, bahwa performa tim hanya dicatat secara manual pada sebuah buku catatan (log book) oleh setiap foreman (atasan) yang membuat sistem penilaian setiap karyawan menjadi lebih sulit karena tidak adanya visualisasi data yang mempermudahan manajemen mengambil keputusan.

Metode agile digunakan dalam penelitian ini karena sistem dapat menyesuaikan terhadap perubahan yang ada pada penilaian kinerja karyawan dan dalam pengambilan spesifikasi sistem dan alur bisnis yang diterapkan. Didalam Metode agile mengenal istlah timebox planning yaitu perencanaan dalam membangun sistem berbasis web dimana melibatkan Supervisor dan karyawan sehingga penilaian tidak lagi dilakukan secara manual yang di record didalam microsoft excel. (Muharom, R.Z,et.al, 2018).

Pengembangan sistem informasi umumnya dimulai dengan mengumpulkan kebutuhan yang diperlukan dalam sistem tersebut. Namun, proses pengumpulan kebutuhan tersebut tidaklah mudah. Selain itu, juga dimungkinkan munculnya masalah baru pada saat pengembangan sistem dilakukan serta keinginan pemilik produk dapa berubah sewaktu-waktu. Dengan kondisi yang telah diketahui tersebut maka diperlukan metode pengembangan sistem yang dapat tanggap terhadap perubahan. Dari berbagai bertode yang ada, metode yang dapat mengatasi perubahan kebuthan yang begitu cepa dalam pembuatan sistem tersebut adalah metode Agile. Agile memiliki beberapa model antara lain Crystal, Extreme Programing (XP), Scrum, dan Kanban. Dari beberapa model tersebut, Scrum dipilih karena menurut penulis yang paling cocok dalam mengembangkan sistem ini karena menuru penulis yang paling cocok dalam mengembangkan sistem ini karena model scrum memberikan kerangka kerja untuk menyelesaikan permasalahan kompleks secara adaptif.

\section{METODE PENELITIAN}

Metode yang digunakan adalah Agile Software Development. Proses ini berasal dari penggunaan model Waterfall yang dianggap sebagai model yang lambat dan tidak konsisten dengan cara pengembang perangkat lunak yang sebenarnya melakukan pekerjaan yang efektif. 
Awalnya, metode Agile disebut sebagai "Lightweight Methods". Kemudian dilanjutkan dengan model pengembangan Scrum.

Menurut (Schwaber \& Sutherland, 2018) disetiap tahap pengembangan, terjadi aktivitas kerja yang terlingkup di dalam suatu pola proses yang dinamakan sprint. Setiap pola proses yang terjadi, akan terdapat seperangkat kegiatan berikut:

1. Backlog Sebuah rincian prioritas pada fitur-fitur yang akan dibangun pada suatu proyek. Isi pada fitur dapat ditambahkan setiap saat.

2. Sprints Kumpulan aktivitas kerja yang dilakukan untuk memenuhi kebutuhan yang ditetapkan dalam backlog dan harus diselesaikan pada waktu yang telah ditentukan (biasanya 30 hari). Perubahan tidak dapat dilakukan pada proses sprint sehingga setiap tim akan bekerja di dalam lingkungan yang stabil.

3. Scrum Meeting Pertemuan yang dilakukan setiap hari oleh Tim scrum untuk membahas apa yang telah dikerjakan sejak pertemuan terakhir, merencanakan dan membahas masalahmasalah yang ada (biasanya 15 menit).

4. Demos Menujukan hasil fungsionalitas yang telah diimplementasikan sehingga dapat dievaluasi oleh pengguna. Demo harus berupa fitur-fitur yang telah diselesaikan sesuai dengan waktu yang telah ditetapkan kanan dari diagram atau pada bagian kepala dari kerangka tulang ikannya. Penyebab permasalahan digambarkan pada sirip dan durinya. Kategori penyebab permasalahan yang sering digunakan sebagai start awal meliputi materials (bahan baku), machines and equipment (mesin dan peralatan), manpower (sumber daya manusia), methods (metode), Mother Nature/environment (lingkungan), dan measurement (pengukuran).

\section{HASIL DAN PEMBAHASAN}

\subsection{Hasil}

\section{Antarmuka (User Interface)}

Tahapan berikutnya penulis membuat perancangan antarmuka (user interface) sebagai mekanisme komunikasi antara pengguna (user) dengan sistem. perancangan antarmuka ini bertujuan untuk membuat tampilan sistem yang efisien, memberikan arus balik yang tepat kepada pengguna dan memberikan kemudahan dalam memakai atau menjalankan sistem agar lebih interaktif dan komunikatif.

\section{a. Halaman Form Login}

Pada halaman login ada dua user yang dapat mengakases login, yaitu admin dan manajer. Dan setiap user memiliki hak akses yang berbeda.

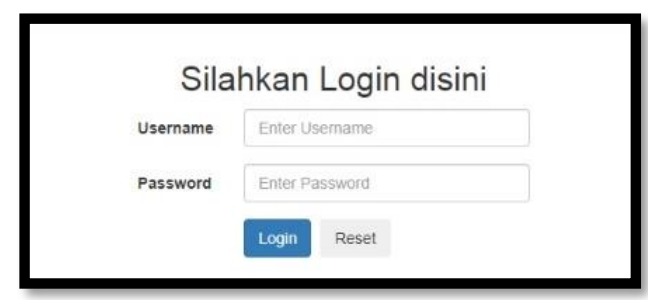

Gambar 4.19 Halaman Form Login 


\section{b. Dashboard}

Pada menu dashboard terdapat gambar analitik status pekerjaan dalam bentuk diagram dan analitik pekerjaan karyawan yang mana didalam menu dashboard tersebut terdapat beberapa item yaitu : data karyawan, data kriteria, data pekerjaan, input status pekerjaan, input nilai karyawan, Analisa karyawan, manajemen user serta laporan.

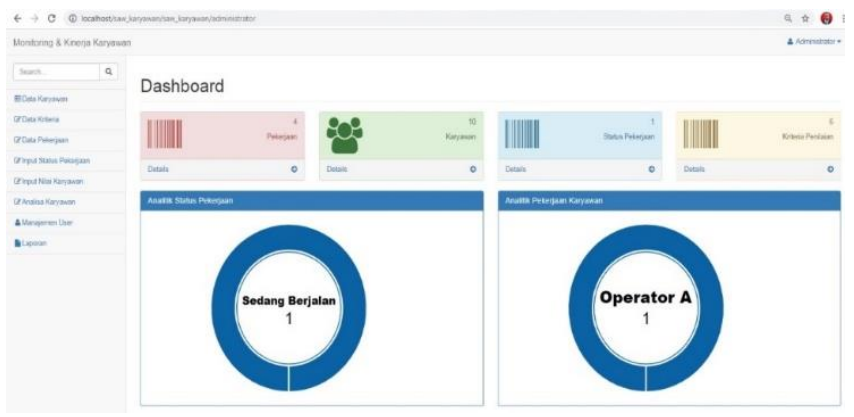

Gambar 4.20 Dashboard

\section{c. Data Karyawan}

Pada data karyawan, pada halaman ini akan ditampilkan data karyawan yang bisa diinput pada halam berikut dengan cara menekan tombol create yang terdiri dari item $I D$ karyawan, nama, posisi, bagian, grade, cabang, tanggal masuk.

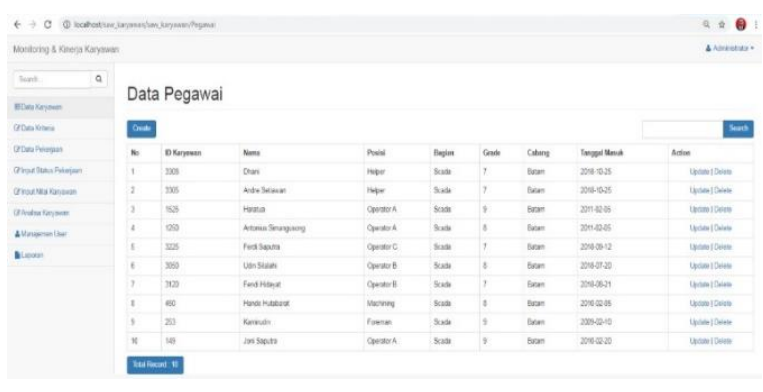

Gambar 4.21 Data Karyawan

d. Data Kriteria

Adapun kriteria penilaian kinerja karyawan pada PT. Cladtek BI Metal Manufacturing terdiri dari Penilaian Teknik Essay (skill,pengetahuan) Penilaian Komparasi, Penilaian Langsung, Penilaian Berdasarkan Perilaku, Penilaian Berdasarkan Kejadian Kritis dan Penilaian Berdasarkan Efektifitas yang mana masing-masing dari kriteria terdapat bobot penilaian yang penulis dapatkan dari hasil wawancara dengan supervisor Sub bagian operator scada 


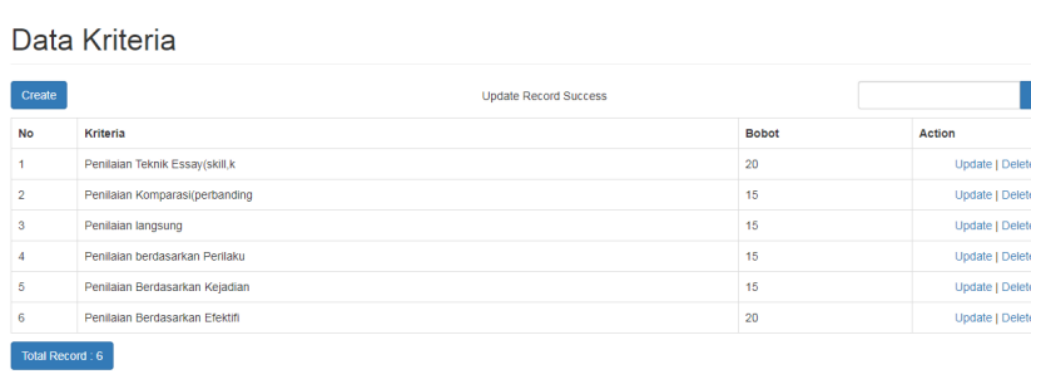

\section{Gambar 4.22 Data Kriteria}

\section{e. Data Pekerjaan}

Pada halaman ini, menampilkan data pekerjaan yang mana terdapat menu create yang berisi nama pekerjaan,deskripsi dan nama proyek.

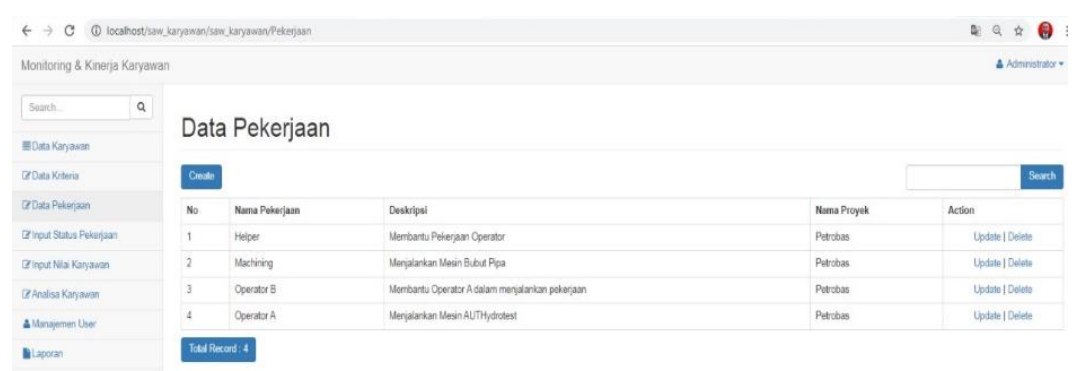

Gambar 4.23 Data Pekerjaan

f. Status Pekerjaan

Pada gambar 4.24 dibawah ini menampilkan data status pekerjaan. Dalam halaman ini kita bisa menginput jenis-jenis pekerjaan yang ada yaitu pada tombol create yang berisi berisi nama karyawan,pekerjaan,status,tanggal mulai, dan tanggal selesai.

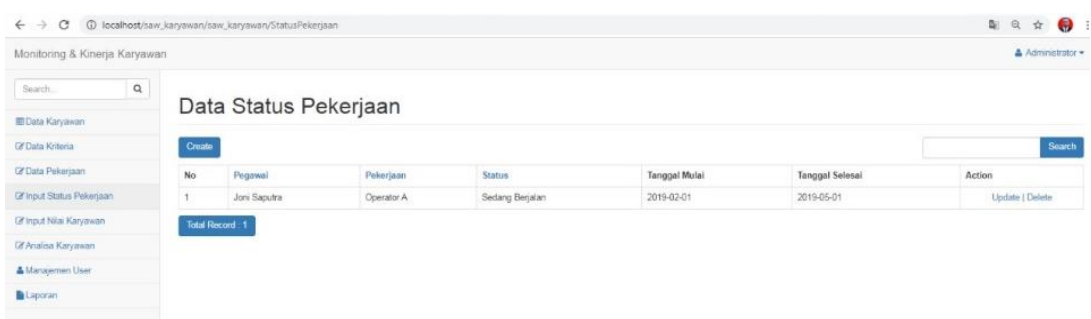

\section{Gambar 4.24 Status Pekerjaan}

\section{g. Hasil Input Nilai Karyawan}

Data nilai karyawan didapatkan dari data karyawan, data pekerjaan serta status pekerjaan yang telah kita inputkan. Dalam halaman ini admin bertugas untuk menginputkan nilai-nilai karyawan didalam aplikasi seperti tampilan 
gambar dibawah ini :

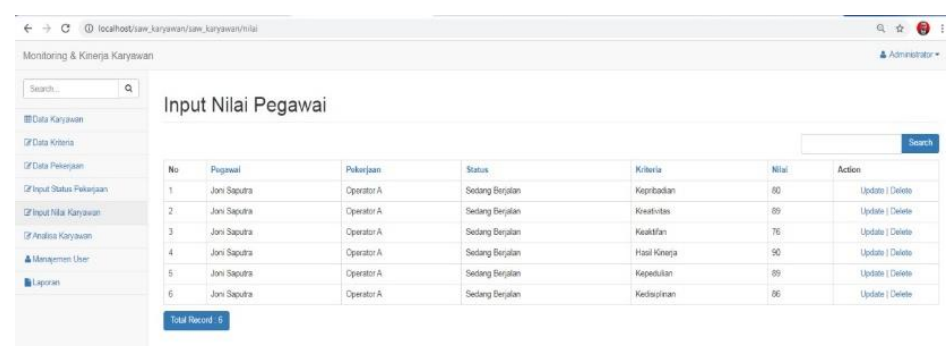

Gambar 4.25 Input Nilai Karyawan

h. Hasil Analisa

Hasil Analisa karyawan yang telah kita inputkan pada menu input nilai karyawan ditampilkan dalam halaman berikut yang tahapannya yang pertama menampilkan tabel nilai kriteria serta nama karyawan, kemudian klick tabel nilai normalisasi untuk mendapatkan hasil normalisasinya. Setelah itu kita lanjutkan dengan cara melakukan proses Analisa.

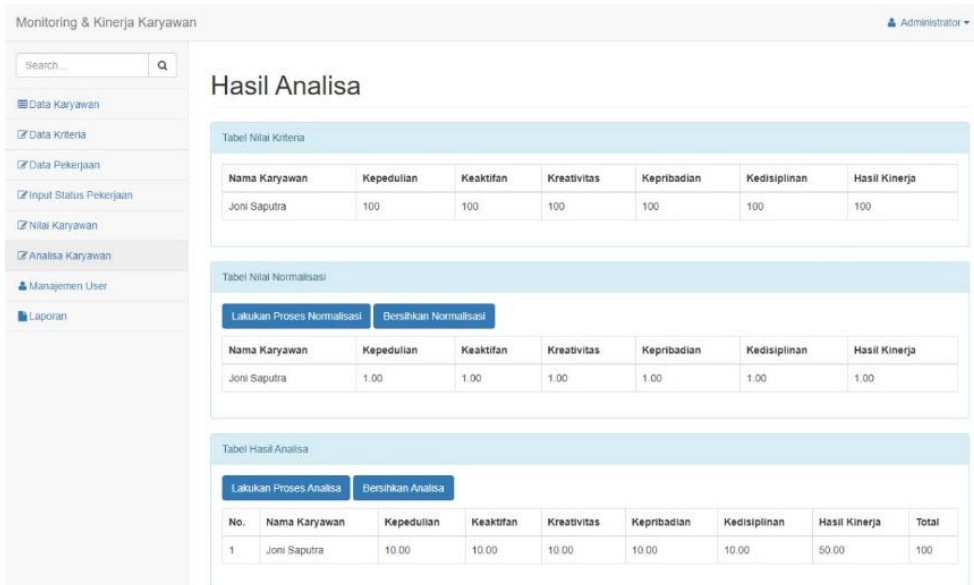

\section{Gambar 4.26 Hasil Analisa}

\section{i. Manajemen User}

Menu ini berfungsi untuk membuatkan login bagi pengguna yang membutuhkan akses kedalam sistem ini.

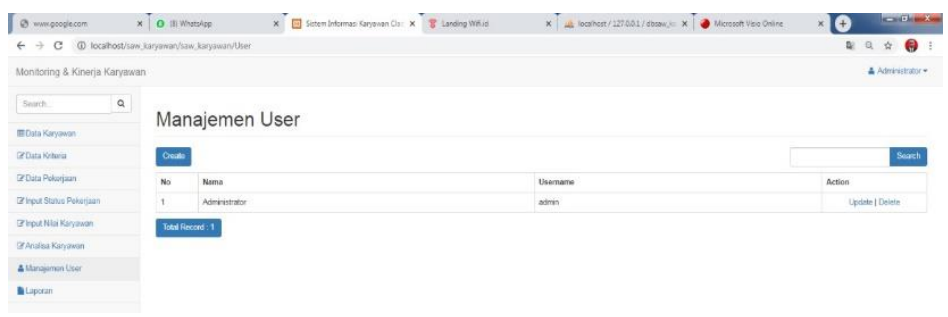




\section{Gambar 4.27 Manejemen User}

j. Laporan

Tampilan halaman pada gambar laporan merupakan hasil akhir dari sistem yang penulis rancang dengan format $C S V$ sesuai permintaan dari tempat penelitian.

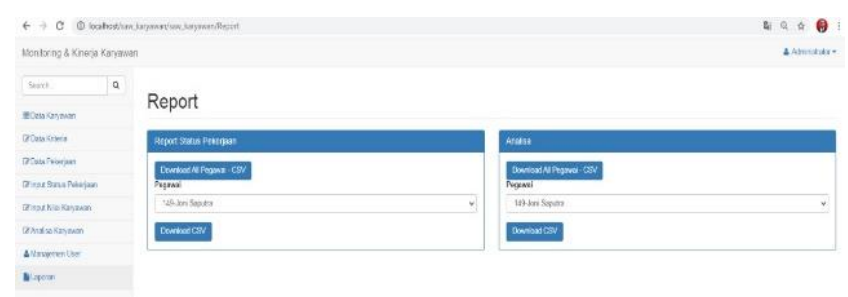

Gambar 4.28 Laporan

\subsection{Pembahasan}

1. Permodelan sistem menggunakan Use-Case Diagram

a. Use-Case Data Pekerjaan

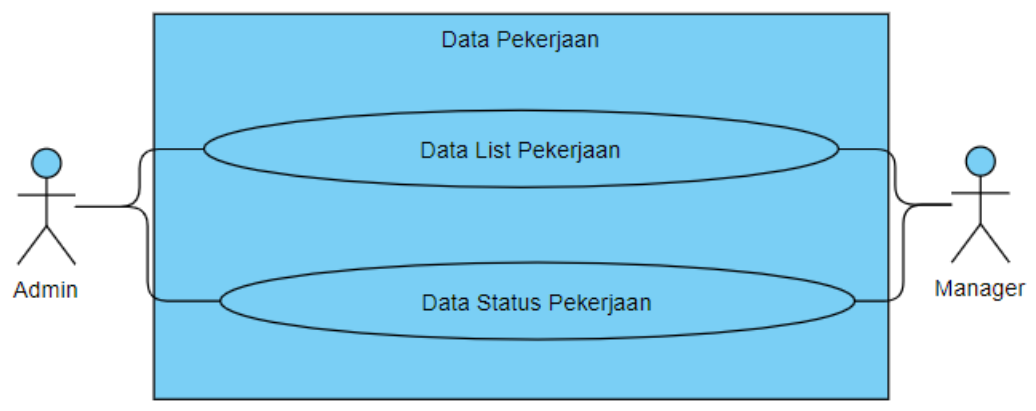

Gambar 4.4 Use-Case Data Pekerjaan

b. Use-Case Data Penilaian Karyawan

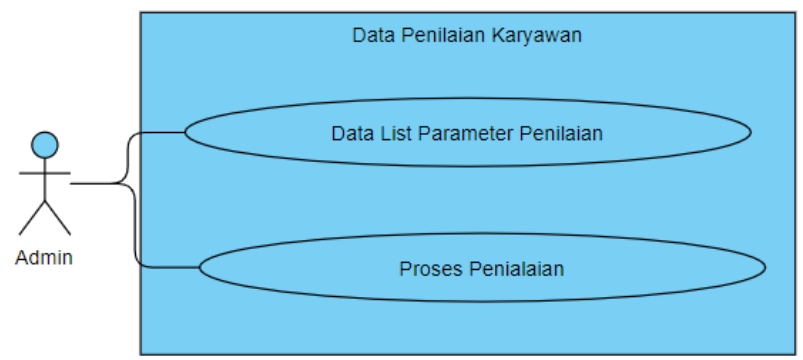

Gambar 4.5 Data Penilaian Karyawan

Kemudian dilanjutkan dengan sequence diagram dalam perancangan sistem ini, pada diagram admin dan manager dapat dilihat sebagai berikut : 
c. Sequence Diagram Admin

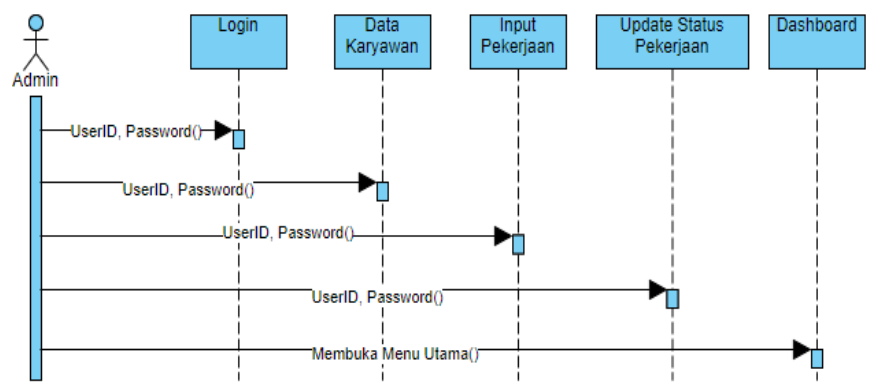

Gambar 4.6 Sequence Diagram Admin

d. Sequence Diagram Manager

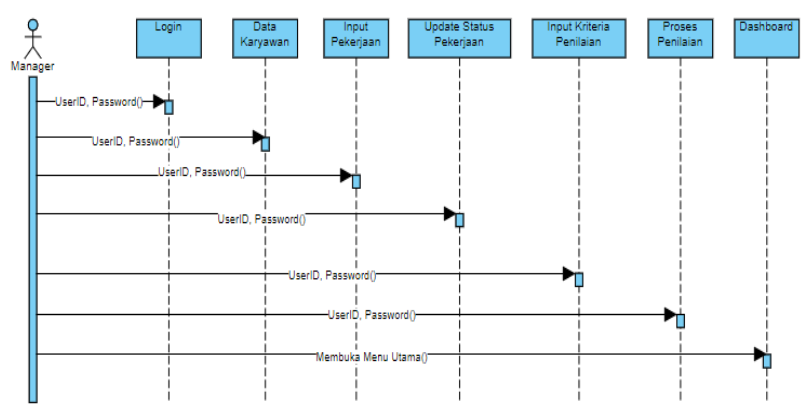

Gambar 4.7 Sequence Diagram Manager

Adapun activity diagram dari perancangan sistem ini dapat dilihat sebagai berikut

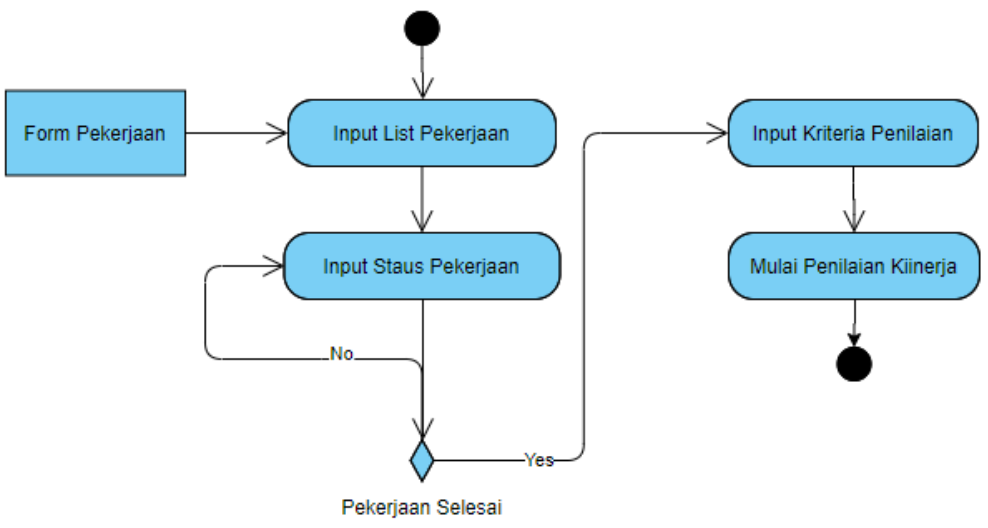

Gambar 4.8 Activity Diagram 


\section{SIMPULAN}

Berdasarkan penelitian yang dilakukan pada PT. Cladtek BI Metal Batam, maka penulis dapat menyimpulkan beberapa hal sebagai berikut yaitu aplikasi yang dibuat dapat mencatat data pegawai, data pekerjaan status pekerjaan, data penilaian kinerja sehingga dalam monitoring karyawan sudah bisa dikatakan menjadi lebih baik dari sebelumnya, aplikasi dibuat berbentuk aplikasi Web yang dapat diakses melalui komputer di mana saja menggunakan media Intranet atau Internet dan yang terakhir dengan menggunakan Aplikasi Monitoring Untuk Penilaian Kinerja karyawan Berbasis Web di PT. Cladtek BI Metal menjadi lebih cepat dan efektif.

\section{SARAN}

Setelah merancang Aplikasi Monitoring dalam Evaluasi Akademik Untuk Penilaian Kinerja PT. Cladtek BI Metal Batam, ada beberapa saran yang harus diterapkan guna pengembangan sistem ini lebih lanjut, yaitu penelitian ini hanya membahas pada penilaian kinerja pada sub bagian Scada yang masih memiliki ruang lingkup yang kecil, sebaiknya untuk penelitian kedepannya agar membahas tentang departemen ataupun seluruh karyawan yang ada PT. Cladtek BI Metal Batam, perlu untuk dikembangkan lebih lanjut fitur pencarian report atau laporan pada aplikasi ini agar perusahaan dapat mencetak hasil penilaian dalam sebuah laporan dan membuat sistem yang mampu menyimpan data rekan penilaian kinerja karyawan dengan menggunakan data di client server.

\section{DAFTAR PUSTAKA}

- C A Wijaya (2018). Sistem Monitoring dan Evaluasi Pengelolaan Program Studi di Institusi Pendidikan Tinggi.

- Edy, Sutrisno, (2016), Manajemen Sumber Daya Manusia, Kencana Prenada Media Group, Jakarta.

- Elmawati, E., \& Wedyawati, V. (2019). Perancangan Sistem Informasi Bencana di Kabupaten Padang Pariaman. Jurnal Pendidikan Teknologi Kejuruan, 2(4), 117-124.

- Hasan, Falih Forat (2018). A Review Study of Information Systems.

- Hendini, A. (2016). Pemodelan UML sistem informasi monitoring penjualan dan stok barang (studi kasus: distro zhezha pontianak). Jurnal Khatulistiwa Informatika, 4(2).

- Hidayat, R. (2017). Aplikasi Penjualan Jam Tangan Secara Online Studi Kasus: Toko JAMBORESHOP. Jurnal Teknik Komputer, 3(2), 90-96. 